\title{
Studio at CSM: Physics, Biology, and Beyond
}

\author{
Patrick B. Kohl, Eric S. Toberer, Judith N. Schoonmaker, H. Vincent Kuo \\ Department of Physics, Colorado School of Mines, 1523 Illinois, Golden, CO 80401
}

\begin{abstract}
Studio and SCALE-UP (developed at RPI and NCSU respectively) have a long history in PER and at the Colorado School of Mines. CSM has been using Studio methods continuously since 1997, when the physics department implemented pilot sections of introductory calculus-based mechanics. Since then, Studio at CSM has expanded slowly at first, with a recent burst of activity. As of 2014, all of Physics I \& II and Biology I are taught via Studio, along with pilot sections of Probability \& Statistics. There are discussions in place to spread Studio to several other courses in the near term, including upper-division physics. In this paper, we focus primarily on the actual spread of Studio at CSM, highlighting challenges and solutions, and reporting on the personal experiences of many of the instructors involved. We will also highlight a developing synergy between the flipped classroom pedagogy and the Studio environment, with some initial data. This synergy holds the potential to accelerate the institutionalization of Studio at CSM.
\end{abstract}

Keywords: Studio, flipped classroom

PACS: 01.40.-d, 01.40.gb, B=D

\section{INTRODUCTION}

The benefits of active learning in STEM have been established with some certainty [1]. Getting active learning into classrooms effectively, however, is a multi-faceted endeavor, involving changes to some or all of the curriculum, pedagogy, environment, and technology being used. Mazur's Peer Instruction [2], for example, involves a pedagogical shift (multiple rounds of voting and student discussion) with carefully chosen questions, and can be facilitated by the use of clickers.

Studio [3], SCALE-UP [4], and TEAL [5] are most recognizable for their redevelopment of the entire learning environment: Instruction takes place in a studio-style room with distributed tables, small groups of students, and little or no physical bias towards the instructor station.

The Colorado School of Mines (CSM) physics department held pilot sections of the first semester of its introductory sequence (Physics I) in a Studio environment starting in the spring of 1997, with all sections held in the Studio since the fall of 2001 [6]. Beginning in 2007, Physics II was also held exclusively in Studio. The details of that conversion process and associated data are available elsewhere [7]. In the past two years, CSM has seen an explosion of activity regarding Studio, centered on the construction of a new Studio room for introductory biology courses, and another for mid- to upper-division physics courses.

In parallel efforts, many at CSM have taken an interest in the flipped classroom approach to STEM teaching. At heart, the flipped classroom involves reordering the course, with knowledge acquisition (assigned readings, prerecorded lectures) taking place out of class (usually before), and in-class time being spent on active learning instead of lecture [8].
The flipped approach has increased in visibility in recent years in part because of the ease of distributing lecture replacement videos via the internet. In the fall of 2013, the CSM physics department flipped two senior-level courses. The instructors involved noted a synergy between Studio and flipping: The Studio environment is designed to facilitate active, studentcentered learning, and the flipped pedagogy is designed to move lecture out of class to create time for active engagement techniques. Starting in the fall of 2014, both classes will be taught using pre-recorded video materials and will be meeting in a Studio-style classroom. Independently, the Studio Biology I course began using flipped video elements in the fall of 2013.

In this paper, our primary goal is to describe the recent growth in Studio at CSM, with a focus on how this particular PER-based reform became common throughout an institution. Also, we will describe our early attempts at flipped classroom instruction in upper division physics, present data, and comment on the union of Studio and flipped instruction. We note that this does not represent a controlled study in either event; rather, this paper represents a tying-together of efforts at CSM so far and an introduction to upcoming work.

\section{INSTITUTIONALIZATION OF STUDIO}

Studio began at CSM largely through the efforts of one or two physics faculty [6,7]. There was no institutional mandate or major funding. The original physics studio was obtained rather opportunistically during the construction of a cross-disciplinary building composed mostly of classroom and computer lab space. Data immediately demonstrated the efficacy of the method for Physics I, but it was ten years before studio was expanded to Physics II (1997-2007). Major obstacles included a lack of faculty formally trained in 

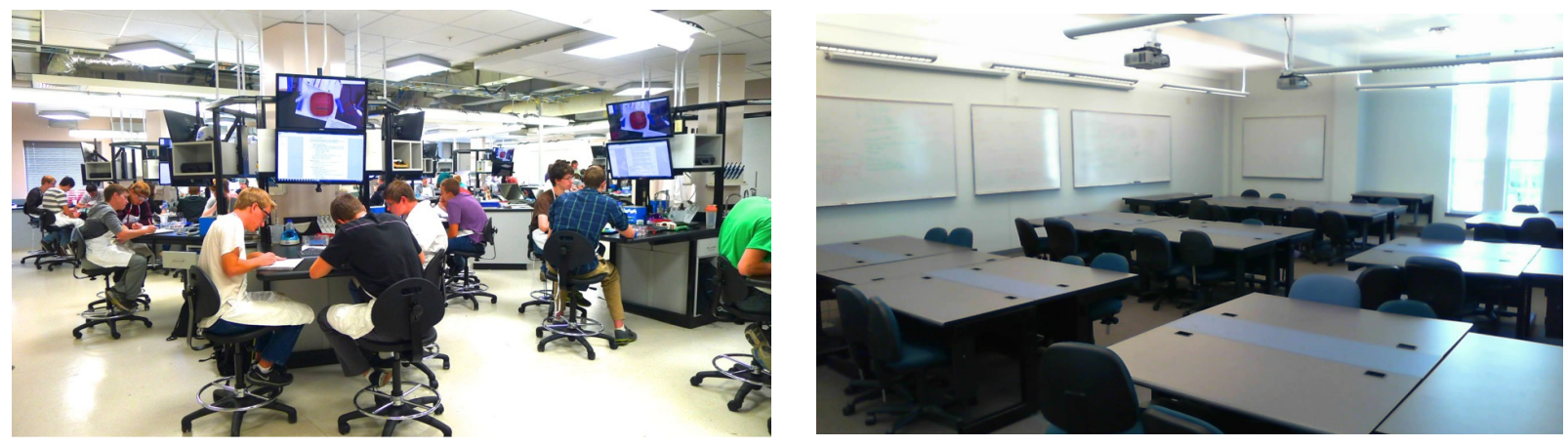

Figure 1. Recently added Studio classrooms at the Colorado School of Mines. Biology Studio (left), upper division physics Studio (right, under development).

using active learning approaches, little faculty time available for course redevelopment, and initial student resistance to Studio. Once these were overcome through new hires and the passage of time, Physics II switched to the Studio format.

At that point, all students at CSM were taking two courses in Studio. Satisfaction and retention were both much improved [7]. Informally, instructors of other courses began discussing the possibility of expanding Studio as early as 2009 , though the availability of space remained an issue. In 2012, the administration appointed a formal committee to plan a Studio biology course, to be held in a renovated and dedicated space on campus. This, of course, required a much larger cash investment than designating Studio space in an alreadyfunded building, and could not have happened without administrative buy-in regarding Studio (see discussion section). Pilot versions of Studio Bio I were first held in spring 2012 in existing space, and the new Studio Biology room opened in the fall of 2013 (Figure 1).

Studio Bio I was developed in close consultation with the physics department, but also reflected significant changes. While the physics version of Studio had involved a hybrid format that retained two hours of lecture per week, Studio Biology was designed to be taught entirely in Studio. Some lecture-like materials were provided using a flipped format - videos and readings assigned as out-of-class preparatory work.

Data for the spring of 2012 to spring of 2014 period for Studio Biology I was immediately positive. The DFW (grade of D, F, or course withdrawal) rate dropped from $10.3 \% \pm 0.9 \%$ for the preceding six traditional semesters to $4.4 \% \pm 1.5 \%$ during the first three semesters of the studio format course. In addition, the instructor of the course compiled a baseline exam that consisted of fifty questions collected from published biology concept inventories [9]. This exam was given as a pretest in both semesters of full Studio implementation, and again as part of the final course exam. The pretest scores were $41 \%$ and $43 \%$ for the fall and spring, with normalized gains for the course averaging $0.70 \pm 0.02$ and $0.82 \pm 0.06$, respectively ( $\mathrm{N}$
$=248$ and 47). Comparable data for the earlier traditional sections do not exist.

The construction of the biology studio was a highprofile event on campus, and many departments (including math, chemistry, and engineering) began discussing the possibility of Studio expansion. In the fall of 2013, math began hosting pilot sections of Studio Probability and Statistics. Studio Biology II is under development.

In the fall of 2013, renovations began on a large computer lab with the goal of creating a second physics Studio (Figure 1) in which to host upper-division physics courses. Five junior and senior physics courses are scheduled to be held in the new physics Studio in the fall of 2014. Notably, only one of those courses is taught by an instructor with a PER background - the rest are taught by non-PER tenure/tenure-track faculty.

\section{FLIPPED PHYSICS AT CSM}

The use of the flipped classroom - in the popular sense of pre-recorded lectures viewed out of class and in-class time used for active learning - appeared at CSM in several courses simultaneously and independently, including but not limited to courses in physics, mathematics, mechanical engineering, and (as previously noted) in Studio Biology I.

Here, we focus on two specific instances of flipped instruction in upper-division physics - a senior-level core course in advanced E\&M \& optics, and a seniorlevel elective in solid state physics. The instructor for one of these courses (E\&M) had a PER background and experience with Studio. The other was a new faculty member with minimal teaching experience. Both had previously expressed dissatisfaction with how visibly disengaged even the higher-performing physics majors appeared during lecture, and were looking for an alternative approach that devoted contact time to more active work. Both independently settled on the flipped classroom approach, and then began meeting semi-regularly during the course development process to share ideas. 



Figure 2. Youtube usage patterns. Left: Typical video (normal incidence E\&M radiation, transmission and reflection coefficients), views per day compared to major course events (130 total views, 50 students enrolled). Right: Monthly solid state video views over a one-year timeframe (summed over all videos, 14 enrolled). Note that solid state is only offered at CSM in the fall semester; most views were international and not affiliated with the course.

With departmental support, the instructors worked during the summer of 2013 to develop video curricula. These videos involved separately recorded video and audio streams, which were then cut, combined and (in the case of the video) sped up or slowed down to control pacing. Videos were typically between three and twelve minutes in length [10].

Once the video curricula were created, the instructors then proceeded to create in-class curricula to fill the time previously filled by lecture. This was perceived to be non-trivial, given the relative absence of pre-packaged active-learning materials at that level (though the E\&M course made some use of the upperdivision E\&M materials from CU-Boulder [11]).

Students were assigned videos to watch before class. Each class session would start with a short recap of the materials, followed by open Q\&A, followed by some combination of clicker questions, group problem solving, guided demos (real or virtual), and such.

Available data from both courses include video usage statistics, course evaluations, course grades, and results from an agree/disagree survey given in-class. The E\&M course also featured pre/post CURrENT [11] testing (though no CURrENT data exists from preflipped years).

Figure 2 shows representative Youtube usage statistics. The leftmost graph is for a particular lecture from the E\&M course and demonstrates an unsurprising pattern: 47 views (not necessarily unique) before lecture with 50 enrolled, with many more views (eventually totaling 150) leading up to the associated homeworks and exam. The rightmost graph shows number of views over a one-year period for a solid state video, and is much more surprising. We see tens of thousands of views, for a class that had 14 enrolled in the fall, and no spring version. These views come from approximately 90 countries. We do not know how, but the solid state video series appears to have achieved international popularity. The solid state instructor speculates that there is a particularly severe shortage of online solid state physics resources, leading to rapid word-of-mouth sharing of the few that do exist.

Course evaluations and qualitative surveys for both courses indicated overwhelming student support for the method. The instructor for E\&M received an average score of 4.0 (out of 4.0) for course effectiveness, compared to a long-term average of 3.7-3.8 for that instructor. The instructor for solid state received a score of 3.7, versus a prior average of 3.3. All students polled indicated a preference for flipping as compared to the traditional mode. Notably, handwritten student comments suggest that to most students "flipped classrooms" are defined mostly by the presence of video lectures, and not by the active learning that takes place during contact time, though when asked directly they stated that they found those activities valuable.

Performance data were less clear. Research-based conceptual inventories at this level are either nonexistent or only moderately aligned with the course topics. Grade-related data are difficult to interpret since year-to-year fluctuations can be large in small classes, and in any event grade distributions between the flipped year and the prior year were similar.

As noted previously, none of the existing instances of flipped upper-division at CSM were developed with Studio in mind (though Studio Biology had flipped elements as soon as it moved beyond a pilot stage). However, given that a lecture-style classroom is not needed for flipped instruction, and given that the Studio environment is designed to facilitate the kinds of inclass activities that occur during flipped instruction, the flipped physics courses were assigned to Studio-style classroom space for their second years. To some extent we are, perhaps, "rediscovering" the all-Studio, nolecture time allocation common to primary implementations of Studio, but with an out-of-class video content delivery method that makes the removal of lecture more tolerable for upper-division theory courses and which is rapidly gaining favor among our traditional faculty. 


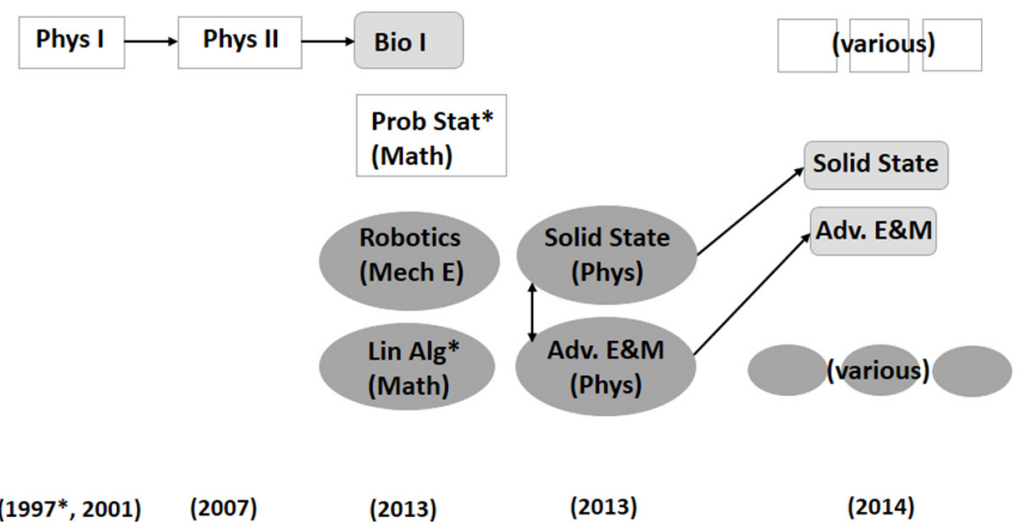

Figure 3. Graphical representation of the evolution of Studio and the flipped classroom at CSM. White squares: Studio classes. Heavy shaded ovals: Flipped classes. Light shaded rounded squares: Both. Arrows indicate classes that worked in close consultation with other classes. Asterisks indicate classes that piloted a technique in only some of the sections taught. All classes shown remain in these formats as of 2014, including several classes not listed scheduled to use these formats in the fall of 2014.

\section{DISCUSSION AND CONCLUSIONS}

In summary, over the last seventeen years, Studio at CSM has gone from a single pilot section of Physics I to three core courses and a host of mid- to upper-level courses. The progression was roughly as follows:

1) One or two faculty adopted the method and championed it, with little support, and with attention to collecting data. The major obstacles to be overcome included finding quality studio space and faculty willing and able to propagate the method for longer than a typical course assignment (here, one to three years).

2) Studio persisted long enough and was demonstrably successful enough for the method to affect space allocation and hiring, leading to permanent facilities and Studio-friendly young faculty.

3) Nearly all of the students at CSM experienced Studio through these courses, and the instructors of these courses and the department head made deliberate efforts to publicize the method on campus and abroad through talks, seminars, and publications.

4) Due to (3), several administrators, department heads, and faculty from across the institution became overtly interested in Studio, leading to a rapid and generally well-funded expansion across campus.

5) Studio being broadly accepted led to the fusion of Studio with other methods that had gained popularity independently, in particular the flipped classroom.

Figure 3 indicates this progression graphically.

One ongoing goal at CSM has been to develop some kind of model for how to reliably guide a new implementation of Studio [see, for example, ref. 7]. At this point, it is no longer clear to us to what extent such a model can exist. Much of what has happened here has depended significantly on local conditions and on the personalities and efforts of a relatively small number of people. Generally, however, it is our opinion that a new implementation of Studio can succeed as long as there are faculty willing to support it long-term, publicize its effects using data-driven arguments, and be flexible regarding Studio classroom space until such time as a local opportunity presents itself. Given that, it is at least possible for Studio to become ubiquitous at an institution that was not a primary developer of the method.

\section{REFERENCES}

[1] Freeman, S., et. al. "Active Learning Increases Student Performance in Science Engineering, and Mathematics." PNAS 2014, doi:10.1073/pnas.1319030111 (2014).

[2] E. Mazur, "Peer Instruction: A User's Manual." Prentice Hall, Upper Saddle River, NJ (1997).

[3] J. M. Wilson, “The CUPLE Physics Studio.” Phys. Teach. 32(12), 518-523 (1994).

[4] R. Beichner, et. al., Student-Centered Activities for Large Enrollment Undergraduate Programs (SCALE-UP) project, In "PER-Based Reform in University Physics", edited E. F. Redish and P. J. Cooney (AAPT, College Park, MD) (2006).

[5] Y. Dori and J. Belcher. "How Does Technology-Enabled Active Learning Affect Undergraduate Students' Understanding of Electromagnetism Concepts?" J. Learn. Sci. 14(2), 243-279 (2005).

[6] T. Furtak and T. Ohno, "Installing Studio Physics." Phys. Teach. 39(12), 11-15 (2001).

[7] P. B. Kohl and H. Vincent Kuo. "Chronicling a Successful Secondary Implementation of Studio Physics." Am. J. Phys. 80, 832-839 (2012).

[8] Vanderbilt teaching guide: Flipping the classroom. http://cft.vanderbilt.edu/guides-sub-pages/flipping-theclassroom/

[9] Fisher, K.M. and Williams, K.S. Concept Inventories/ Conceptual Assessments in Biology (CABs). http://www.sci.sdsu.edu/CRMSE/files/Concept_Inventor ies_in_Biology_20110325.pdf (2012).

[10]CSM PHGN 462 course website, video directory. http://ticc.mines.edu/csm/wiki/index.php/Video_Resourc es_-_Phys_462

[11]"Research-Based Course Materials and Assessments for Upper-Division Electrodynamics (E\&M II)" Charles Baily, Michael Dubson and Steven J. Pollock, PERC Proceedings 2012, AIP Press (2012) 